\title{
Hippocampal Brain Derived Neurothropic Factor Levels in Response to Anaerobic Physical Exercises
}

\author{
Mohammad Zulkarnain ${ }^{1}$, Rostika Flora ${ }^{2}$, Juliastuti ${ }^{1}$, Anita Apriany ${ }^{1}$, Dewi Pujiana ${ }^{1}$, \\ Septi Andrianti ${ }^{1}$ \\ ${ }^{1}$ Faculty of Medicine, Universitas Sriwijaya, South Sumatera, Indonesia \\ ${ }^{2}$ Faculty of Public Health, Universitas Sriwijaya, South Sumatera, Indonesia
}

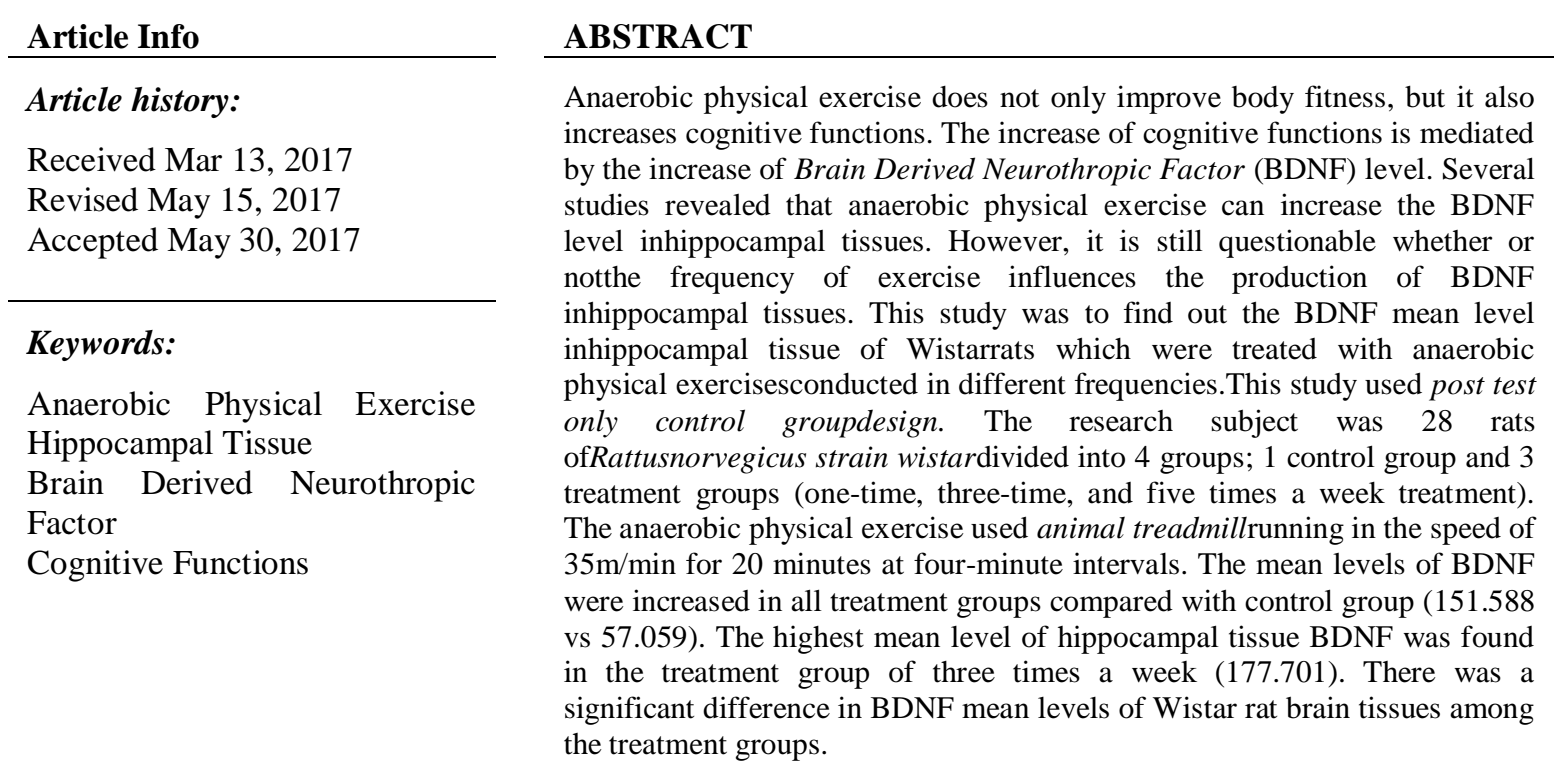

Copyright $@ 2017$ Institute of Advanced Engineering and Science. All rights reserved.

\section{Corresponding Author:}

Rostika Flora,

Faculty of Public Health, Universitas Sriwijaya, South Sumatera, Indonesia.

Email: rostikaflora@gmail.com

\section{INTRODUCTION}

Physical exercise is a series of physical activities providing physical burden on the body regularly, systematically, and sustainably through proper exercise program [1].This exercise may have effects on cardiovascular, pulmonary, and musculoskeletal systems and central nervous system [2]. Physical exercise should be set as a program and conducted regularly with correct training load, duration, and frequency [3]. Frequency of exercise is one of the components that must be considered in performing physical exercise. Frequency of exercise refers to the number of training sessions conducted over a certain period [4].

One of the physical exercises is anaerobic physical exercise. This physical exercise is high-intensity one that, in its implementation, is supported by the formation of adenosine triphosphate (ATP) from anaerobic glycolysis process for a short time when the distribution of $\mathrm{O}_{2}$ to muscles is not adequate to support oxidative phosphorylation [5].Anaerobic physical exercise requires high energy and high amount of ATP. ATP itself is coming from phospocreatine (PCr).Anaerobic capasitycan be assessed from the amount of $\mathrm{PCr}$ produced in muscles, buffer capacity, and volume of muscle contraction [6].

Apart from improving cardiac functions, physical exercise can also improve cognitive functions through functional repair of hippocampus and neurogenesis [2]. Neurogenesis in hippocampus plays an important role in learning process and memory. Neurogenesis occurs in subgranularzone of hippocampal 
dentate gyrus [7]. Hippocampus induces cellular responses to repetitive and external stimuli that are very essential in relation to narrative learning and spatial memory [8]. The presence of new neurons becomes the basis for structural plasticity in hippocampus by forming new synapses in hippocampal neuronal circuits through the generation of axon and neuritis [9].

A neurotrophin which plays an important role in memory formation is brain derived neurotrophic factor (BDNF) which acts as a mediator of neurogenesis and contributes to dendritic development. BDNF is found in brain hippocampus, cerebral cortex,and amygdala. The highest concentration of BDNF is found in hippocampal tissues [10]. BDNF is a member of neurotrophin family, a group of structural polypeptides related to growth factor [11]. The expression of BDNF is very sensitive to the development factors and environment. The signals of BDNF can increase neurogenesis, electrophysiology activities, and other reflective processes [12].

BDNF has been reported to be able to influence learning ability and memory since it is located on regions that regulate growth and repairing nerves, and neuroplasticity [13]. The increase of BDNF level will increase the production and life of brain cells [14]. Some studies state that anaerobic physical exercise can increase the BDNF level of hippocampal tissue. However, there has been no evidence whether the frequency of exercise influences the production of hippocampal-tissue BDNF. This study was to find out the mean level of hippocampal-tissue BDNF in Wistar rats treated with anaerobic physical exercises in different frequencies.

\section{RESEARCH METHOD}

This was experimental study applying post test control group design. This study was conducted in animal house of Laboratorium Bio Sains Riset Palembang and had ethical approval from Ethical Comission of Medicine Faculty, Universitas Sriwijaya No.075/Kepkrsmhfkunsri/2016.

This study used Wistar rats as animal testing. The animals were male, healthy, aged 6-8 weeks, and weighed 80-150 grams.In adaptative period, the rats were given ad libitum access to food and water, and their cages were always kept clean. Before being used as research subjects, the rats were given acclimatization for 1 week. The samples of this study were 28 rats which were devided into 4 groups as follows.

P1: Control group, not given physical exercise.

P2: Treatment group, given anaerobic physical exercise with the frequency of once a week for four weeks. P3: Treatment group, given anaerobic physical exercise with frequency of three times a week for four weeks. P4: Treatment group, given anaerobic physical exercise with frequency of five times a week for four weeks.

The treatment of anaerobic physical exercise was done in the evening for 4 weeks by placing the rats on animal treadmilland run the treadmill in the speed of 35 meters per minute for 20 minutes at an fourminute interval. When the interval of treadmill speed was lowered into $20 \mathrm{~m} / \mathrm{min}$ for 1 minute. Before the treatments were given, the rats were weighed and their body temperature was measured. After the treatments were finished, the rats were taken out from animal treadmilland immediately their body weight and body temperature were measured. At the end of the treatments, the hippocampal tissue of rats was collected (the protocol of anaerobic physical exercise in this study was following Flora et al's study) [15]. After that, homogenate of hippocampal tissue was prepared and the level of BDNF was measured. The level of BDNF was measured using ELISA kit BDNF for rat from Elabscience Biotech Co. Ltd. The data collected from this study were analyzed using software SPSS version 20.

\section{RESULTS AND ANALYSIS}

\subsection{Mean Levels of Hippocampal BDNF}

The results of laboratory tests showed that the mean levels of hippocampal tissue BDNF were increased in groups treated with anaerobic physical exercise for one-time a week, three times a week, and five times a week compared with control group. The details of BDNF mean levels are shown in Table 1.

Table 1. Mean Levels of Hippocampal-Tissue BDNF in Control Group and Treatment Groups

\begin{tabular}{ccc}
\hline Group & $\mathrm{n}$ & Mean $\pm \mathrm{SD}(\mathrm{pg} / \mathrm{ml})$ \\
\hline Control & 7 & $57.059 \pm 1.20$ \\
Anaerobic: $1 \mathrm{x} /$ week & 7 & $154.409 \pm 2.11$ \\
Anaerobic: $3 \mathrm{x} /$ week & 7 & $177.701 \pm 1.88$ \\
Anaerobic: $5 \mathrm{x} /$ week & 7 & $122.655 \pm 1.55$ \\
Total & & \\
\hline
\end{tabular}




\subsection{Comparison of Hippocampal-Tissue BDNF Mean Levels between Control Group and Treatment Groups}

To find out whether or not there was a significant difference in BDNF mean levels of hippocampal tissue between control group and treatment groups, one-way Anovawas applied.Based on the statistical analysis, it was found that there was a significant difference $(\mathrm{p}=0.0005)$ in the mean levels of BDNF between control group and treatment groups. The results of analysis can be seen in Table 2.

Table 2. Comparison of Hippocampal-Tissue BDNF Mean Levels between Control

\begin{tabular}{cccc}
\multicolumn{5}{c}{ Group and Treatment Groups } \\
\hline Group & $\mathrm{n}$ & Mean \pm SD $(\mathrm{pg} / \mathrm{ml})$ & $\mathrm{p}^{*}$ \\
\hline Control & 7 & $57.059 \pm 1.20$ & 0.0005 \\
Anaerobic: $1 \mathrm{x} /$ week & 7 & $154.409 \pm 2.11$ & \\
Anaerobic: 3x/week & 7 & $177.701 \pm 1.88$ & \\
Anaerobic: $5 \mathrm{x} /$ week & 7 & $122.655 \pm 1.55$ & \\
Total & 28 & & \\
\hline$p^{*}$ One-way ANOVA & & &
\end{tabular}

\subsection{Comparison of Hippocampal-Tissue BDNF Mean Levels among Groups Treated with Anaerobic Physical Exercises in Different Frequencies}

To find out whether or not there was a significant difference in the mean level of hippocampal tissue BDNF among groups treated with anaerobic physical exercises of once a week, three times a week, and five times a week, statistical analysis of one-way Anova was applied. Based on the analysis, it was found that there was a significant difference $(\mathrm{p}=0.0005)$ in the mean level of BDNF among the groups treated with anaerobic physical exercise in different frequencies. The results of analysis can be seen in Table 3.

Table 3. Comparison of Hippocampal-Tissue BDNF Mean Levels among the Groups Treated with Anaerobic Physical Exercises in Different Frequencies

\begin{tabular}{cccc}
\hline Anaerobic Groups & $\mathrm{n}$ & Mean \pm SD $(\mathrm{pg} / \mathrm{ml})$ & $\mathrm{p}^{*}$ \\
\hline 1x/ week & 7 & $154.409 \pm 2.11$ & 0.0005 \\
3x/week & 7 & $177.701 \pm 1.88$ & \\
$5 \mathrm{x} /$ week & 7 & $122.655 \pm 1.55$ & \\
Total & 21 & & \\
\hline$p^{*}$ One-way ANOVA & & &
\end{tabular}

Based on the study, it was found that the BDNF mean levels of treatment groups were increased compared with those of control group $(57.059 \pm 1.20 \mathrm{pg} / \mathrm{ml})$. BDNF levels in groups of three times a week were higher $(177.701 \pm 1.88 \mathrm{pg} / \mathrm{ml})$ than those of once a week $(154.409 \pm 2.11 \mathrm{pg} / \mathrm{ml})$ and five times a week $(122.655 \pm 1.55 \mathrm{pg} / \mathrm{ml})$. The increase of BDNF levels in groups treated with anaerobic physical exercises occurs because physical exercise is one of the factors that contribute to increase BDNF and cAMP Response element-binding protein (CREB). The study of Gomez-Pinillaet al (2001) showed that mRNA BDNF is positively correlated to CREB of animal testing which was measured immediately after physical exercise [16]. According to Cotman (2007) and Zolad et al (2008), hippocampus contains high level of BDNF. In rats and humans, the level of BDNF can be increased by physical exercise [13],[14].

The results of this study were in line with those of Vaynman et al (2004). He found that animal testings which were given physical exercises revealed an increased level of mRNA BDNF $(130 \pm 13 \%)$ and TrkBreceptors $(120 \pm 6 \%)$ in hippocampus [10]. The present study was also similar to Berhctold (2005) in which routine physical exercises using wheel running exercise can increase BDNF gene expression and protein level of rat brain tissues [16].

BDNF is a member of the neurotrophinfamily, a group of polypeptide structure which is related to growth factor [11]. The expression of BDNF proteins is found the highest in hippocampus especially in the axon of granule cells of dentate gyrus [17]. The expression of BDNF can be increased by physical exercise and the increase can improve congitive function. Physical exercise especially endurance one is known to have beneficial effects on the brain health and cognitive function [13].The effects of physical exercise to brain can be obviously seen on hippocampal dentate gyrus, a part of brain that has a role in learning process and memory. The significance of physical exercise specifically is to increase the blood flow in human hippocampus. The morphological changes which were mediated by physical exercise may occur in dendritic spines.In addition, synaptic plasticity and neurogenesis process in dentate gyrusmay also be increased [13]. According to Cerutti (2012), physical exercise has many positive effects to brain. There was a significant 
correlation $(\mathrm{p}<0.05)$ between physical exercise and the increase of memory and cognitive functions. This could probably be as an impact of physical exercise to the increase of BDNF causing neurogenesis in hippocampus occurs and the plasticity in the brain increased [18]. The changes of synaptic palsticity related to physical exercise occur in the same regions of hippocampal tissues, and neurogenesis is stimulated by running exercise. Newly-born cells have their functional roles in this process [19].

In this study, the highest increase of BDNF mean level was found in a treatment group given anaerobic physical exercise with the frequency of 3 times a week. This might occur for anaerobic physical exercise conducted in this study was included in high-intensity one requiring recoverytime to obtain the benefits from the physical exercise. This finding has been in line with American College of Sports Medicine (2009) that reccomendsphysical exercise be done in the frequency of 3 times a week in order to get maximum benefits [20]. Physical exercise with excessive frequency and burden can disturb the recovery and muscular works. It is not recommended to exercise everyday because body needs recovery after physical exercise [21].

Fox (1993) states that recovery can be seen from two functional body systems i.e cardiovascular system and energy metabolism system. The recovery occuring in cardiovascular function on systemic level lasts in a short period (within minutescale). However, in energy metabolism system, recovery requires more time (within hour scale). Recovery to glycogen store needs longer time (within day scale), and the one to lactic acid lasts for \pm 60 minutes [22]. Lactic acid is formed as a result of physical exercise conducted in high intensity and longer period. If the load of physical exercise given is excessive and the recovery time is not optimal, our body will be physically and logically affected [23]. The accumulation of lactic acid can lead to muscular pains when one is doing sports continually. Lactic acid absorbed by blood may create acidosis metabolic. The depletion of energy store and the increase $\mathrm{pH}$ of muscles as a result of lactic acid accumulation will trigger muscle fatigue. Muscle fatigue is body defensive mechanism to protect muscles, and it occurs when the muscles are not capable to response given stimuli with the same contraction level [5].

Rasmussen et al (2009) conducted a study in humans to find out plasma BDNF levels and in animal testings to assess the BDNF mRNA expression of hippocampal tissue. The study in humasfound that physical exercise increased plasma BDNF levels, but in a state of recoverythe level was decreased to the point of basalt. Similarly, the results of animal testings indicated that physical exercise increased BDNF mRNA expression, but in a state of recoverythe levels were decreased but not to the point of basalt. This is because the hippocampus is the largest producer of BDNF (70-80\%) compared to other organs [24].

The benefits of physical exercise to the increase of BDNF levels on cognitive function have been investigated extensively. Costa et al (2012) conducted a study in young adults and adult mice treated with moderate physical exercise using a treadmill. The research subjects were divided into 4 groups with different frequency of exercise i.e0, 1, 3 and 7 days / week for 8 weeks. The study found that the frequency of physical exercise does not modify the memory of adult mice. Physical exercise with a frequency of 1 day/week can increase the levels of proBDNF and BDNF. On the other hand, physical exercise with a frequency of 7 days/week may reduce the levels of proBDNF [25].

A study of Gomez-Pinillaet al (2001) showed that BDNF levels of animal testings after running inside the wheel for 3 and 7 days were increased [16]. According to Nieman (2011), there was a positive correlation between the dose of exercise and the frequency and duration of physical exercise to the improved performance. When physical exercise can be done in a week, both in frequency and duration, the positive effect will last long. However, if physical exercise conducted in a long time with the addition of the duration and frequency of exercise, it can reduce the benefits of physical exercise itself [26]. According to Shiffer et al (2011), physical exercise with high intensity can create lactate accumulation in blood. Besides, it will also cause the release of BDNF [27]. The study of Rasmussen et al (2009) revealed that lactate supported the release of BDNF in major secretion regions in central nerve system during exercise and a half of BDNF is released from human brain during physical exercise [28].

High-intensity physical exercise which is performed continuously in healthy individuals with duration of a few minutes can lead to the increased levels of BDNF with large variations [29]. According to Meeusenet al (2012), high-intensity physical exercise in the form of strength training not only has a positive effect on muscle tissue, but this practice also produces adaptive changes in the central nervous system [30].

\section{CONCLUSION}

Anaerobic physical exercise conducted in different frequency of exercise could increase the mean level of Brain Derived Neurothropic Factor (BDNF) of hippocampal tissue. There was a significant 
difference $(\mathrm{p}<0.05)$ in the mean level of hippocampal BDNF among the groups given anaerobic physical exercises for 1 time, 3 times, and 5 times a week. Anaerobic physical exercise conducted in different frequency of exercise for 4 weeks will promote adaptive changes in central nervous system.

\section{ACKNOWLEDGEMENTS}

The researchers are very grateful to Ministry of Research, Technology and Higher Education for having granted this project through Hibah Pascasarjana Year 2016.

\section{REFERENCES}

[1] Astrand P. O., et al., "Textbook of work physiology: physiological bases of exercise," New York, McGraw-Hill, 2003.

[2] H. V. Praag, "Exercise and the brain: something to chew on," Trends Neurosci, vol/issue: 32(5), pp. 283-290, 2009.

[3] Shen, et al., "The Effect of Different Intensities of Treadmill Exercise on Cognitive Function Deficit Following a Severe Controlled Cortical Impact in Rats," International Journal of Molecular Sciences, 2013.

[4] J. W. Kraemer, "Progression and Resistance Training," Physical Fitness and Sports, Washington, D. C., 2005.

[5] S. Lauralee, "Human Physiology from Cells to Systems," EGC, Jakarta, 2014.

[6] K. Sahlin, "Muscle Energetics during Explosive Activities and Potential Effects of Nutrition and Training," Sports Med, vol/issue: 44(2), pp. S167-S173, 2014.

[7] Gould E. and C. G. Gross, "Neurogenesis in Adult Mammals: Some Progress and Problems," J Neurosci, vol. 22, pp. 619-623, 2002.

[8] Cameron, et al., "Adult Neurogenesis Produces a Large Pool of New Granule Cell in the Dentate Gyrus," J. Comp. Neurol, vol. 435, pp. 406-417, 2001.

[9] Ramirez A. V., et al., "Integration of new neurons into functional neural networks," J Neurosci, vol. 26, pp. 1223712241, 2006.

[10] Vaynman S., et al., "Hippocampal BDNF mediates the efficacy of exercise on synaptic plasticity and cognition," European Journal of Neuroscience, vol. 20, pp. 2580-2590, 2004.

[11] K. D. Binder and E. H. Scharfman, "Brain-Derived Neurotrophic Factor Growth Factors, vol/issue: 22(3), pp. 123$131,2004$.

[12] Murray P. S. and Philip V. H., "An Overview of Brain-Derived Neurotrophic Factor and Implications for Excitotoxic Vulnerability in the Hippocampus," Hindawi Publishing Corporation International Journal of Peptides, 2011.

[13] C. W. Cotman, et al., "Exercise builds brain health: key roles of growth factor cascades and inflammation," Trends Neurosci, vol. 30, pp. 464-472, 2007.

[14] Zoladz J. A., et al., "Endurance training increases plasma brain-derived neurotrophic factor concentration in young healthy men," J Physiol Pharmacol, vol. 59, pp. 119-132, 2008.

[15] R. Flora, et al., "Myocardial Damage after Continuous Aerobic and Anaerobic Exercise in Rats," Med J Indones, vol/issue: 22(4), pp. 209-214, 2013.

[16] F. G. Pinilla, et al., "Spatial learning induces neurotrophin receptor and synapsin I in the hippocampus," Brain Res., vol. 904, pp. 13-19.

[17] Berchtold N. C., et al., "Exercise primes a molecular memory for brain-derived neurotrophic factor protein induction in the rat hippocampus," Neuroscience, vol/issue: 133(3), pp. 853-861, 2005.

[18] Conner J. M., et al., "Distribution of brain-derived neurotrophic factor (BDNF) protein and mRNA in the normal adult rat CNS: evidence for anterograde axonal transport," J Neurosci, vol. 17, pp. 2295-2313, 1997.

[19] N. Cerutti, "The Effect of Exercise on the Brain," Medlink Conference at Nottingham, 2012.

[20] J. D. Bronzino, et al., "Maturation of long-term potentiation in the hippocampal dentate gyrus of the freely moving rat. Hippocampus, vol/issue: 4(4), pp. 439-446, 1994.

[21] American College of Sports Medicicine, “A Clinician's Guideto Exercise Prescription," Lippincott Williams \& Wilkins, 2009.

[22] R. Flora, "Heart and Physical Exercise," Palembang, Unsri Press, 2015.

[23] E. Fox, et al., "The Pysiological Basis of Physical Education and Athletics," Philadelphia, Saunders College, 1993.

[24] Quinn E., "Preventing Overtraining - When Less is More," 2008. http://sportmedicine.about.com diakses 15 April 2016.

[25] P. Rasmussen, "Evidence for the release of BDNF from the brain during exercise," 2009. http://ep.physoc.org/content/early/2009/08/07/expphysiol.2009.048512. 
[26] M. S. Costa, et al., "The Impact of Frequency of Moderate Exercise on Memory and Brain Derived Neurotrophic Factor Signalling in Young Adult and Middle-Aged Rats," Neuroscience, vol. 222, pp. 100-109, 2012.

[27] D. Nieman, "Exercise Testing and Prescription," McGraw-Hill International Companies, Newyork, pp. 165-179, 2011.

[28] T. Shiffer, et al., "Lactate Infusion at Rest Increases BDNF Blood Concentration in Humans," Neuroscience letters, vol. 488, pp. 234-237, 2011.

[29] Rojas V. S., et al., "Acute Brain Derived Neurotrophic Factor and Cortisol Response to Ramp Incremental Exercise to Exhaustion in humans," Brain Res, vol. 1121, pp. 59-65, 2006.

[30] Meeusen, et al., "Prevention, Diagnosis, and Treatment of the Overtraining Syndrome," Medicine and Science in Sport Exercise, 2012. 